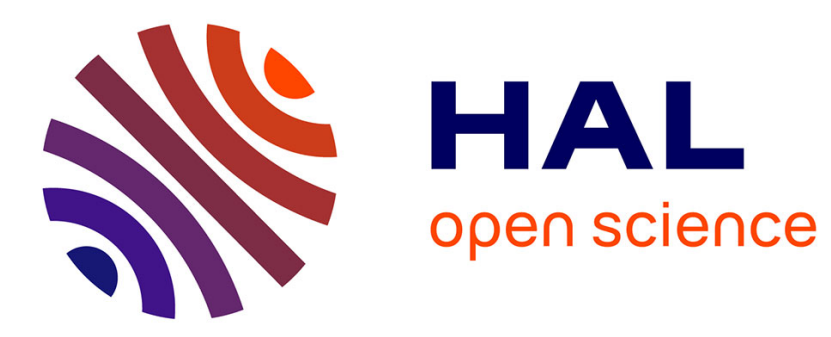

\title{
High-pressure compressor blade dynamics under aerodynamic and blade-tip unilateral contact forcings
}

Alain Batailly, Mathias Legrand, Antoine Millecamps, François Garcin

\section{To cite this version:}

Alain Batailly, Mathias Legrand, Antoine Millecamps, François Garcin. High-pressure compressor blade dynamics under aerodynamic and blade-tip unilateral contact forcings. ASME Turbo Expo 2014, ASME, Jun 2014, Düsseldorf, Germany. 10.1115/GT2014-25675 hal-01130542

\section{HAL Id: hal-01130542 \\ https://hal.science/hal-01130542}

Submitted on 11 Mar 2015

HAL is a multi-disciplinary open access archive for the deposit and dissemination of scientific research documents, whether they are published or not. The documents may come from teaching and research institutions in France or abroad, or from public or private research centers.
L'archive ouverte pluridisciplinaire HAL, est destinée au dépôt et à la diffusion de documents scientifiques de niveau recherche, publiés ou non, émanant des établissements d'enseignement et de recherche français ou étrangers, des laboratoires publics ou privés.

\section{(c)(1)}

Distributed under a Creative Commons Attribution| 4.0 International License 


\title{
High-pressure compressor blade dynamics under aerodynamic and blade-tip unilateral contact forcings
}

\author{
Alain Batailly ${ }^{1, *}$, Mathias Legrand ${ }^{1}$, Antoine Millecamps ${ }^{2}$, François Garcin ${ }^{2}$
}

\begin{abstract}
Recent studies focused on the numerical prediction of structural instabilities that may arise in rotating components of an aircraft engine. These instabilities are commonly classified into two categories: those induced by aerodynamic phenomena (such as the pressure applied on the blade by the incoming air flow) and those related to structural phenomena (such as potential blade/casing contacts). Based on an existing numerical strategy for the analysis of rotor/stator interactions induced by unilateral contacts between rotating and static components, this paper aims at combining both types of instabilities and provides a qualitative analysis of structural interactions that may arise within the high-pressure compressor of an aircraft engine. The aerodynamic pressure on the blade is simplified as a sinusoidal external load whose frequency depends on the number of upstream guide vanes. Results are presented both in time and frequency domains. Detailed bifurcation diagrams and Poincaré maps underline the fundamental differences in the nature of the witnessed interactions with and without aerodynamic loading on the blade.

Keywords

Nonlinear dynamics, contact mechanics, aeronautical engine, rotor/stator interactions, vibrations.

1 - Structural Dynamics and Vibration Laboratory, McGill University, 817 Sherbrooke West, McConnell Engineering Bldg, Room 122, H3A 0C3, Montréal, Québec, Canada

2 - Snecma, site de Villaroche, Moissy-Cramayel, 77550, France

* Corresponding author: Tel.: +15143985321; fax: +1514398 7365. E-mail address: alain.batailly@mcgill.ca

\section{Comportement dynamique d'une aube de compresseur haute-pression sous l'effet cumulé d'un chargement aérodynamique et de contraintes unilatérales de contact}

\author{
Alain Batailly ${ }^{1, *}$, Mathias Legrand ${ }^{1}$, Antoine Millecamps $^{2}$, François Garcin ${ }^{2}$
}

\begin{abstract}
Résumé
Plusieurs études récentes ont eu pour objet la simulation numérique des instabilités structurelles pouvant survenir dans des machines tournantes telles que des moteurs d'avion. Typiquement, ces instabilités sont séparées en deux catégories: celles relatives aux phénomènes aérodynamiques (liés par exemple à la pression imposée sur l'aube par le flux d'air) et celles relatives à des phénomènes uniquement structurels (comme le contact aube/carter). En se basant sur l'utilisation d'une méthode numérique dédiée à l'analyse d'interactions aube/carter initiées par des contacts entre parties tournante et fixe, les travaux présentés dans cet article ont pour objectif d'analyser conjointement les deux types d'instabilité précédemment citées et de fournir une analyse qualitative des types de régimes d'interactions pouvant survenir dans un moteur d'avion. La pression aérodynamique est modélisée à l'aide d'un chargement externe d'amplitude sinusoïdale et dont la fréquence dépend du nombre de redresseurs en aval. Les résultats sont donnés dans les espace temporel et fréquentiel. Les différences fondamentales de nature entre les différentes interactions simulées avec et sans pression aérodynamique sont mises en évidence par des diagrammes de bifurcation détaillés et des cartes de Poincaré.
\end{abstract}

\section{Mots-clés}

Dynamique nonlinéaire, mécanique numérique du contact, moteur aéronautique, interaction rotor/stator, vibrations.

1 - Laboratoire de Dynamique des Structures et Vibrations, Université McGill, 817 Sherbrooke Ouest, Pavillon McConnell, Salle 122, H3A-0C3, Montréal, Québec, Canada 2 - Snecma, site de Villaroche, Moissy-Cramayel, 77550, France

Auteur à contacter : Tél. : +15143985321; fax : +15143987365. Courriel : alain.batailly@mcgill.ca

\section{Introduction}

Among the components of an aircraft engine, blades from both the compressor and the turbine are the ones most subject to failures [1]. In standard operating conditions, many physical phenomena explain such weakness from high and low cycle fatigue to corrosion and creep failures. Mechanical damage stemming from object ingestion or structural contact used to be considered as accidental or abnormal in conventional aircraft engine designs. However, the use of tighter operating clearances in order to optimize the engine efficiency and reduce fuel consumption has been constraining designers to include structural contacts - such as blade-tip/casing or blade-tip/abradable coating contactswithin standard operating conditions which has a significant impact on the prediction of blades life expectancy. Consequently, rotor/stator interactions within aircraft engines have become an important field of interest for designers and manufacturers. The numerical developments exposed in this paper are part of a global strategy devoted to the design of blades robust to unilateral contact conditions.

In the literature of rotordynamics, the term rotor/stator interaction [2] involves a large class of distinct mechanical systems and their corresponding dynamical responses. In this paper the focal point is made on the blade response to external loadings, be 
it through (1) unilateral contact with the surrounding casing [3] or (2) the aerodynamic loading initiated by close guide vanes $[4,5]$ and subsequent noise issues [6]. Possible contact with neighbouring blades [7] along shroud interfaces is not accounted for. To the author's knowledge, all these interactions have been analysed independently of one another. Recent numerical investigations [3] for the simulation of rotor/stator interactions initiated by unilateral contacts between a blade-tip and the surrounding casing have revealed consistency with experimental observations [8] made inside a vacuum sealed environment. The interaction phenomenon of interest in those studies consist of a single blade clamped on its root and impacting the surrounding casing over which is deposited an abradable coating. For such an interaction scenario, uncoupling aerodynamic and structural effects seems questionable: high amplitudes of vibration due to aerodynamic loading may indeed lead to blade/casing contacts.

Based on the numerical strategy previously introduced in [9], and assuming a weak aerodynamic coupling, this paper focuses on the combination of aerodynamic and contact induced blade vibrations. Numerical simulations are carried out over a properly selected rotational frequency range and a particular attention is paid to the nature of the results once steady state is reached: phase diagrams and Poincaré maps (which are a snapshot of the phase space once per forcing period) are constructed in order to reveal the nature of the blade motion. The first section of the paper briefly recalls the theoretical foundations of the employed numerical strategy. The modeling of the aerodynamic loading as well as its implications in the equations of motion are then introduced. Results from contact simulations are detailed in the third section and a more in-depth analysis of the time responses is carried out in the last section.

Note: For the sake of confidentiality, all numerical data have been normalized and units are not provided.

\section{Theoretical considerations}

The numerical strategy used in this paper is based on the combination of 3D finite element models and an explicit time marching procedure [9]. Contact forces are computed with a Lagrange multipliers based approach [10]. The removal of abradable coating is modeled through the compression of plastic elements [11]. While this is not an intrinsic limitation of the numerical strategy, the casing is here considered perfectly rigid: it is thus represented by means of a mathematical profile, additionally, it is slightly deformed along a two-nodal diameter free vibration mode — an oval shape - as a way to initiate contact. Such deformation was identified in [3] as a necessary condition for the initiation of interactions. A component mode synthesis method [12] based on the Craig-Bampton [13] approach is used to build a reduced order model of the blade that accounts for centrifugal stiffening. In the end, the 3D finite element model of the blade which contains about 42,000 degrees of freedom (DoF) comes down to a $95 \mathrm{DoF}$ reduced order model including $30 \mathrm{DoF}$ for contact management along the blade tip and 65 modal coefficients. The Campbell diagram of this model is pictured in Fig. 1 for the first bending and torsion modes denoted respectively $1 \mathrm{~B}$ and $1 \mathrm{~T}$.

The convergence of the blade reduced order model eigenfrequencies with respect to the 3D finite element model has been checked but is not detailed here for the sake of brevity. Similarly, convergence of the time integration algorithm and modal convergence have been checked prior to any simulation.

Contact simulations are highly nonlinear since contact areas

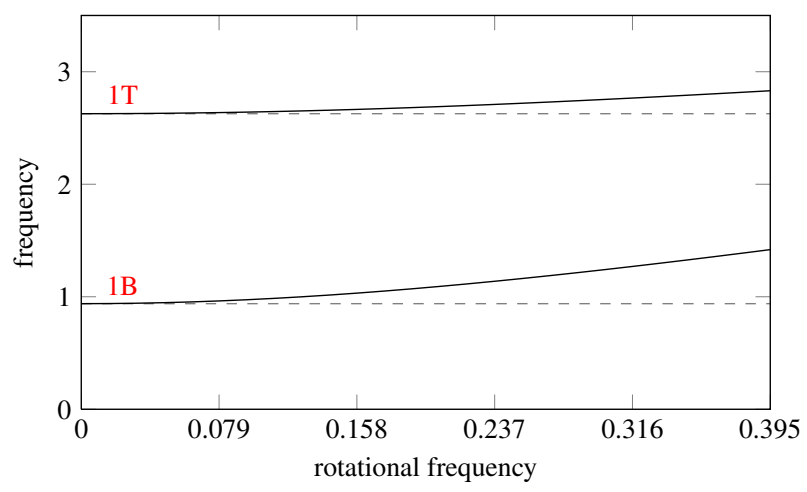

Figure 1. Campbell diagram

are a priori unknown and the respective hybrid contact pressure/displacement boundary conditions are part of the solution. The equation to be solved may be written as follows:

$\mathbf{M} \ddot{\mathbf{X}}(t)+\mathbf{D} \dot{\mathbf{X}}(t)+\mathbf{K}(\Omega) \mathbf{X}(t)+\mathbf{F}(\mathbf{X}(t))=\mathbf{0}$

where $\mathbf{X}$ is the reduced displacement vector, $\mathbf{M}, \mathbf{D}$ and $\mathbf{K}(\Omega)$ are respectively the mass, damping and rotational frequency dependent stiffness reduced matrices and $\mathbf{F}$ is the contact force applied on the blade tip. As mentioned in the introduction, it is intended to simulate contact interactions combined with an equivalent aerodynamic pressure loading. The physical considerations exposed in the next section justify that this loading mathematically becomes a forcing term $\mathbf{F}_{a}(t)=\mathbf{F}_{a} \sin \left(f_{a} t\right)$. It yields that the equation to be solved is:

$\mathbf{M} \ddot{\mathbf{X}}(t)+\mathbf{D} \dot{\mathbf{X}}(t)+\mathbf{K}(\Omega) \mathbf{X}(t)+\mathbf{F}(\mathbf{X}(t))=\mathbf{F}_{a}(t)$

Equation (1) characterizes a nonlinear dynamic system as very possibly multistable, meaning that several stable states may coexist for identical sets of parameters (such as the structural damping coefficient or the initial blade/casing clearance configuration for instance) depending on the initial conditions. The addition of a forcing term — as in Eq. (2) — for such a system is a wide field of research in many areas such as mathematics [14], electrical systems [15] and biology [16] to name a few. In particular, the forcing term may be responsible for bifurcations and thus requires particular attention.

\section{Aerodynamic loading}

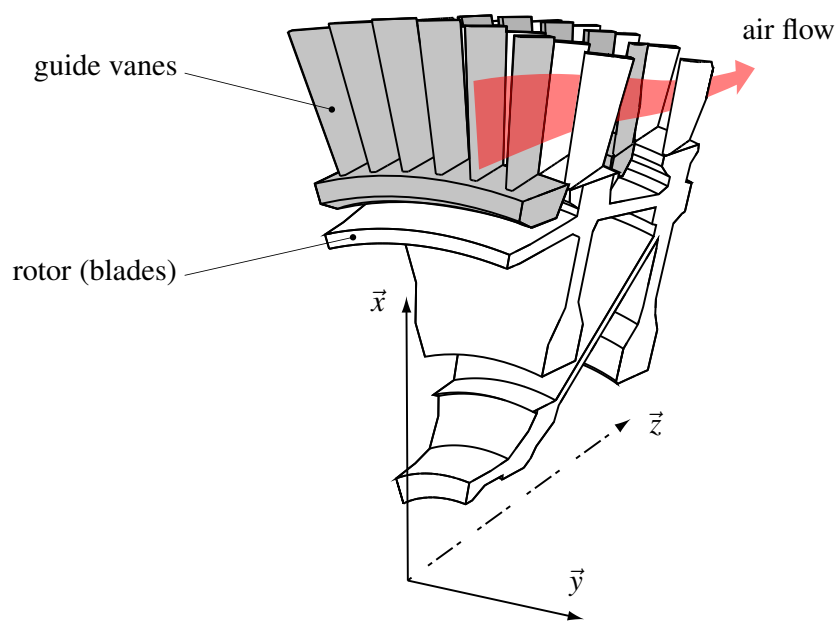

Figure 2. Partial view of a high-pressure compressor 
The blade of interest belongs to the high-pressure compressor of an aircraft engine partially drawn in Fig. 2. Its profile is depicted in Fig. 3. By design, the pressure of the air flow inside the compressor increases from a stage to another. This variation of pressure between the air upstream of the blade and downstream of the blade is properly reflected by the application of an aerodynamic pressure field on the blade pressure side as schematically depicted in Fig. 3. As the blade rotates, the amplitude of this

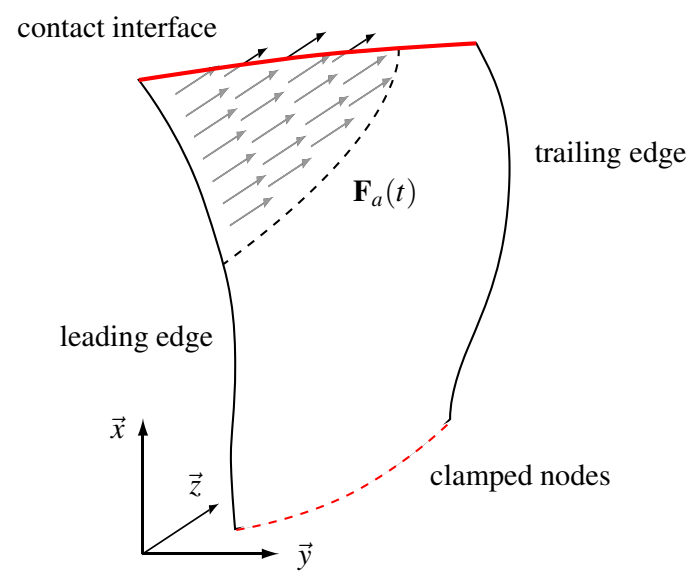

Figure 3. Blade of interest

pressure field significantly variates depending on the blade environment, specifically the relative angular position of the blade with respect to surrounding downstream guide vanes pictured in Fig. 2.

The time-dependent pressure field is denoted $\mathbf{F}_{a}(t)$, it is assumed sinusoidal and its frequency $f_{a}$ is: $f_{a}=\Omega \times N_{g v}$ where $\Omega$ is the rotational frequency of the blade and $N_{g v}$ is the number of guide vanes at the considered stage. In this study, $N_{g v}=60$. As shown in Fig. 3, the area of application of this pressure loading is concentrated around the blade tip and the leading edge in agreement with CFD simulations. Because CFD simulations are only used here to define the amplitude of the pressure field, the coupling between structural vibrations and aerodynamics is said to be weak. In order to fully benefit from the small dimension of the blade reduced order model, the pressure field $\mathbf{F}_{a}(t)$ is projected on the associated basis. The subsequent reduction error ${ }^{1}$ achieved with this reduced-order model is greater than $0.01 \%$. The linear forced response of the blade is depicted in Fig. 4.

\section{Contact simulations}

Equation (2) is solved over 50 revolutions with and without aerodynamic loading over a properly selected rotational frequency range centered on the blade nominal rotational frequency. To some extent, the contact force $\mathbf{F}(\mathbf{X}(t))$ may also be seen as a forcing term in the sense that $\mathbf{X}=\mathbf{0}$ cannot be solution of Eq. (2): contact will occur due to the casing deformation. However, due to structural damping and abradable coating removal, $\mathbf{X}=\mathbf{0}$ is a possible steady state.

For each simulation, it is assumed that steady state is reached after about 35 revolutions and a Fourier transform of the time responses is computed over the remaining 15 revolutions. Put side by side, these Fourier transforms form an interaction map such as the ones plot in Figs. 5 and 6. The amplitude of vibrations

\footnotetext{
${ }^{1}$ The reduction error is the relative comparison of the strain energy associated with the static deformation of the finite element model undergoing the pressure loading with the strain energy associated with the static deformation of the reduced order model undergoing the reduced pressure field.
}

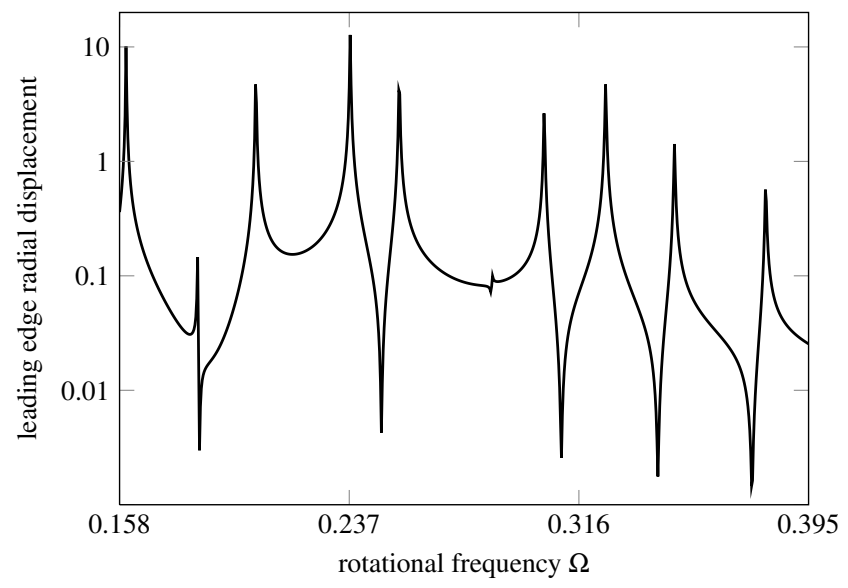

Figure 4. Blade forced response under aerodynamic loading

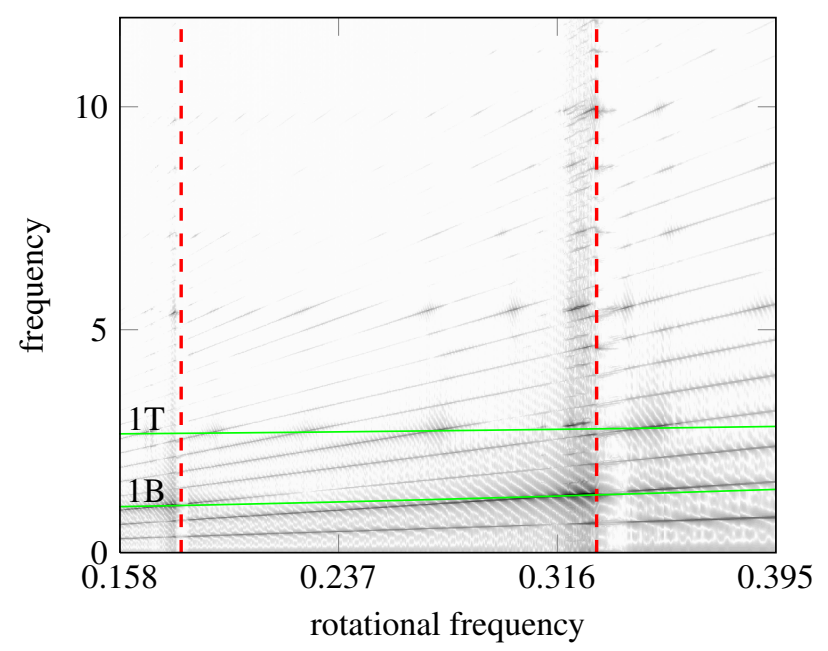

Figure 5. Interaction map without aerodynamic loading

are depicted with a colour code — identical for both maps - from white to black respectively for lowest to highest computed levels.

As shown in Fig. 5, there are a few critical rotational frequencies $((---))$ for which elevated amplitude of vibrations are detected without aerodynamic loading. In this case, the position of the highest peaks of amplitude are typically located at the intersection of engine order lines - for which $f=k \Omega, k=1, \ldots, n$ and that appear as black lines radiating from the origin - and the eigenfrequencies $1 \mathrm{~B}$ and $1 \mathrm{~T}((-))$. Higher eigenfrequencies do not feature significant peaks of vibration.

The introduction of the time-dependent external forcing term in the equations leads to a much more complicated interaction map. An increased number of resonances are found at the intersections between engine order lines and eigenfrequencies in Fig. 6. The significant contribution of higher frequencies in the vibratory response of the blade is underlined by the comparison of the two spectrograms given in Figs. 7(a) and 7(b) for $\Omega=0.395$ respectively without and with aerodynamic loading. Because the number of guide vanes is much greater than the number of contact areas on the casing, the excitation frequency of the aerodynamic loading $f_{a}$ is much greater than the fundamental harmonics associated with contact interactions. In addition, the spectrogram plotted in Fig. 7(b) emphasizes that the frequency content of the spectrum at the vicinity of $f_{a}$ is also very dense which highlights the nonlinear features of contact conditions and their interaction with the aerodynamic loading.

Both interaction maps and spectrograms underline the influence of aerodynamic loading on the blade vibratory response. 


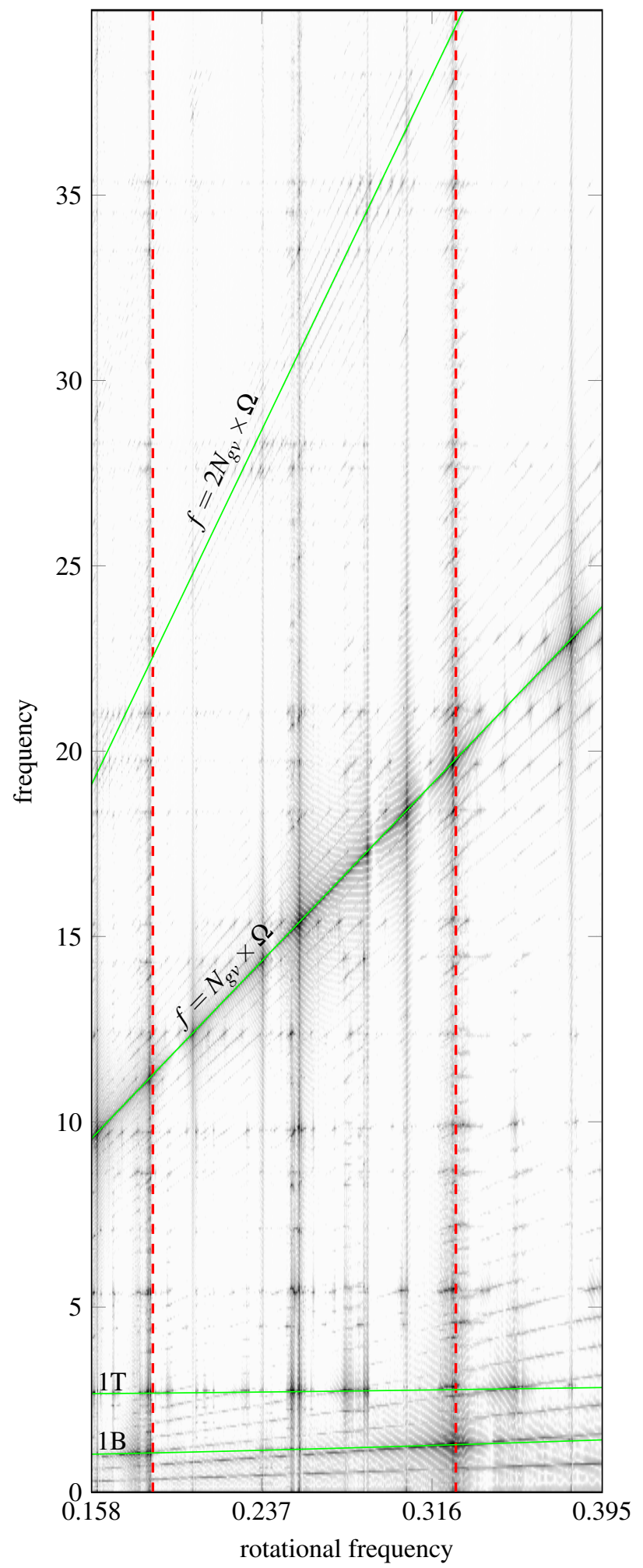

Figure 6. Interaction map with aerodynamic loading

However, the participation of higher frequency modes as well as the increased number of critical rotational frequencies are not fundamentally unexpected. These quantitative results are essentially a reminder that the phenomenon of interest is highly nonlinear. A more detailed analysis could be carried out focusing the evolution of abradable coating removal as well as contact locations on the casing. Though, at this point, the lack of experimental data obstructs any numerical/experimental comparison. For this reason, it is proposed to focus instead on the nature of the solution. Previous results $[3,9]$ underlined that the simulation of contact interactions typically lead to periodic steady states. So far, the employed numerical strategy did not allow for the identification of any other type of motion such as quasi-periodic or chaotic motions.

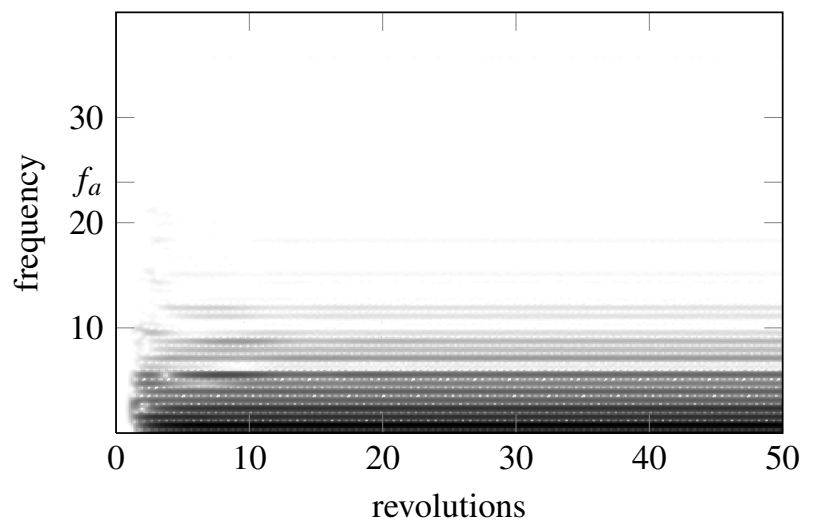

(a) Without aerodynamic loading

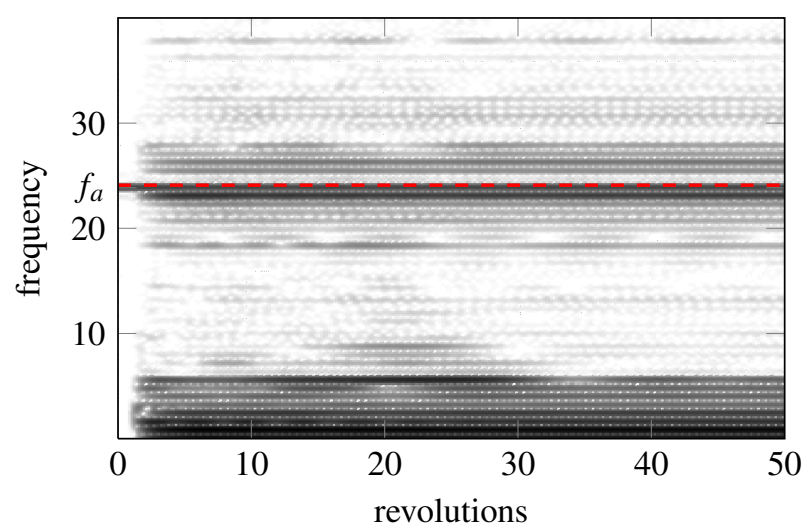

(b) With aerodynamic loading

Figure 7. Spectrograms for $\Omega=0.395$.

\section{Nonlinear qualitative analysis}

An extensive post-processing of the simulations with aerodynamic loading allowed for the identification of a few rotational frequencies for which phase diagrams and Poincaré maps features are unexpected. Four rotational frequencies are considered in the following, denoted $\Omega_{1}, \Omega_{2}, \Omega_{3}$ and $\Omega_{4}$. Associated contact simulations are carried out over 500 revolutions in order to plot precise phase diagrams and Poincaré maps. For each of these rotational frequencies, four quantities are depicted in Fig. 8: (1) the axial displacement $u_{\mathrm{LE}}(t)$ of the leading edge, (2) the axial displacement of the leading edge $u_{\mathrm{LE}}(t)$ over the last computed period (which is half a revolution due to the two symmetric contact areas along the casing circumference), (3) the phase diagram in the plane $\left(u_{\mathrm{LE}}(t), \dot{u}_{\mathrm{LE}}(t)\right)$ over the last 50 periods and (4) the associated Poincare map. In Fig. 8, the amplitude of the blade forced response due to the aerodynamic loading without structural contacts is pictured in $((---))$.

- Separation: at $\Omega_{1}$, the steady state is perfectly periodic and it is visible that the amplitude of the blade leading edge axial displacement matches the amplitude of the blade forced response due to sole aerodynamic loading which is an indication that blade/abradable coating contact is lost. Consequently, the phase diagram is an ellipse and the Poincaré map features a single dot.

- Quasi-periodic motion: at $\Omega_{2}$, the blade response in Fig. 9(b) exhibits a quasi-periodic motion. The final amplitude of 

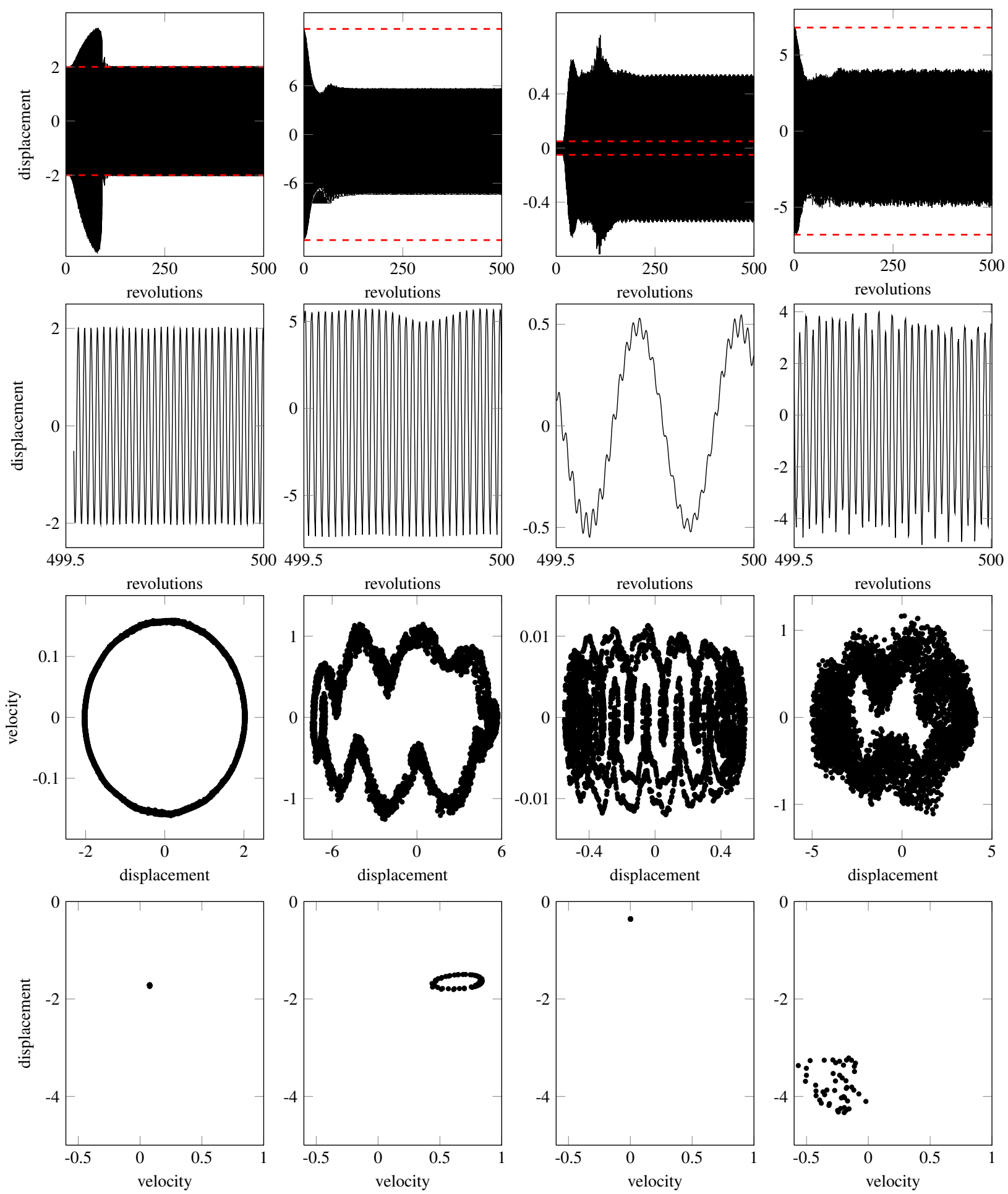
(a) $\Omega_{1}=0.205$
(b) $\Omega_{2}=0.306$

(c) $\Omega_{3}=0.316$

(d) $\Omega_{4}=0.383$

Figure 8. SUPERIMPOSITION OF TIME RESPONSE, A ZOOM OVER ITS LAST PERIOD, PHASE DIAGRAM AND POINCARE MAP WITH AERODYNAMIC LOADING 
vibration is lower than the one under aerodynamic loading: the abradable coating constrains the blade displacement and intermittent contact occurs repeatedly over time. Once steady state has been reached, the contact configuration does not evolve thus the abradable elements undergo elastic deformations only. The related phase diagram underlines the steady state which appears as a closed orbit in the Poincaré map.

- Periodic motion: as visible in Fig. 8(c), at $\Omega_{3}$, the final level of vibration is much higher than the one computed solely with aerodynamic loading. In this configuration, the blade dynamics seems mostly guided by contact constraints. The phase diagram features a more complex trajectory but the motion is still perfectly periodic since a single dot appears in the Poincaré map.

- Chaotic motion: finally, at $\Omega_{4}$, the blade displacement is constrained by the abradable coating since the final amplitude is lower than the one obtained with the blade forced response. A close inspection of the last period of this time response exhibits a very fluctuating amplitude of the signal which leads to a cloud-like phase diagram. The Poincaré map underlines the chaotic nature of the motion since no clear orbit appears.

Contact simulations for $\Omega_{2}$ and $\Omega_{4}$ were also carried out without aerodynamic loading for the sake of comparison. For each rotational frequency, four quantities are depicted in Fig. 9: (1) the axial displacement $u_{\mathrm{LE}}(t)$ of the leading edge over time, (2) the axial displacement of the leading edge $u_{\mathrm{LE}}(t)$ over the last computed period, (3) the phase diagram in the plane $\left(u_{\mathrm{LE}}(t), \dot{u}_{\mathrm{LE}}(t)\right)$ over the last 50 periods and (4) the associated Poincaré map. While the time scale does not easily allow for the rendering of the amplitude variation observed during transient, it clearly appears that for both rotational frequencies, the steady states are perfectly periodic since the Poincaré maps feature a single dot. Results obtained for any other rotational frequencies without aerodynamic loading lead to similar observations: if contact is not lost after a few revolutions, then a perfectly periodic steady state is established.

\section{Conclusion}

An existing time domain numerical strategy for the simulation of blade/casing structural interactions is extended to aerodynamic loading applied over a portion of the blade pressure side. By doing so, a periodic forcing term appears in the equations of motion and the point of the paper is to assess the possible qualitative changes this term implies on the nonlinear dynamical system of interest. This system is composed of a single high-pressure compressor blade rotating within a statically deformed rigid casing over which circumference a thin layer of abradable coating is deposited. Contact simulations carried out with and without aerodynamic loading are first quantitatively compared using interaction maps. The coupling between aerodynamic excitation frequency and structural contact excitation frequencies is underlined. A more qualitative comparison is then accomplished which highlights the fundamental differences in the nature of the stable solution obtained with aerodynamic loading. In particular, quasiperiodic and chaotic motions are now observed while contact simulations only predict periodic motions.

As part of a global strategy for the development of blade designs robust to contact interactions, the presented results suggest that accounting for aerodynamic loading is crucial.
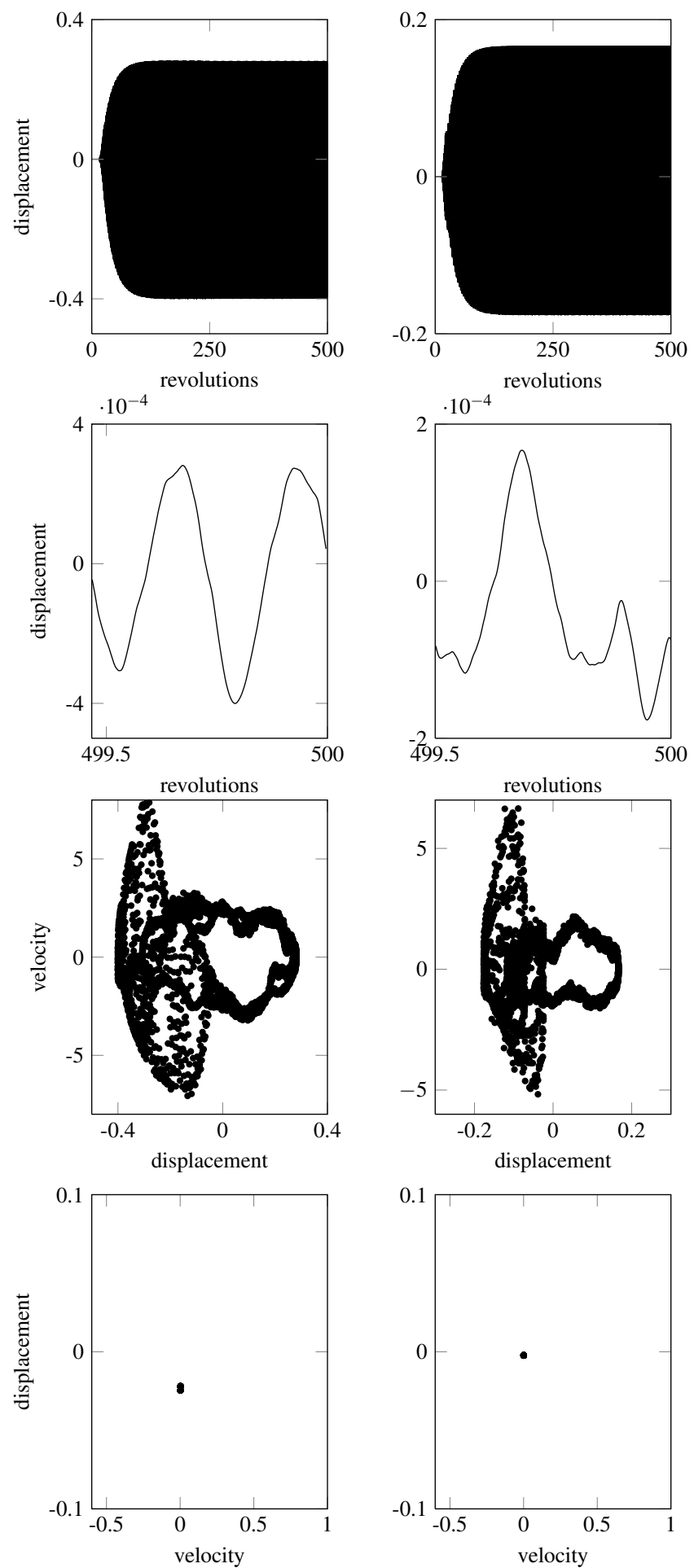

(a) $\Omega_{2}=0.306$

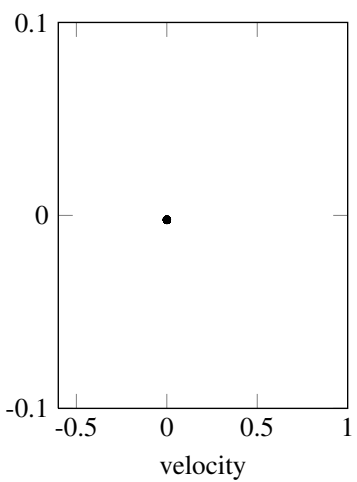

(b) $\Omega_{4}=0.383$

Figure 9. Superimposition of time response, a zoom over its last period, phase diagram and poincare map without aerodynamic loading 


\section{Acknowledgement}

Thanks go to Turbomeca and Snecma for their technical and financial support.

\section{References}

[1] T. J. Carter, Common failures in gas turbine blades, Engineering Failure Analysis 12 (2005) 237-247, DOI:10.1016/j.engfailanal.2004.07.004.

[2] C. Morfey, Rotating pressure patterns in ducts: their generation and transmission, Journal of Sound and Vibration 1 (1) (1964) 60-87, DOI:10.1016/0022-460X(64)90007-0.

[3] A. Batailly, M. Legrand, A. Millecamps, G. F., Numericalexperimental comparison in the simulation of rotor/stator interaction through blade-tip/abradable coating contact, Journal of Engineering for Gas Turbines and Power 134, DOI:10.1115/1.4006446.

[4] N. Arndt, A. Acosta, C. Brennen, T. Caughey, Experimental investigation of rotor-stator interaction in a centrifugal pump with several vaned diffusers, Journal of Turbomachinery 112 (1990) 98-108, DOI:10.1115/1.2927428.

[5] R. Dring, H. Joslyn, L. Hardin, J. Wagner, Turbine rotorstator interaction, Journal of Engineering for Power 104 (1982) 729-742, DOI:10.1115/1.3227339.

[6] W. Copeland, L. Crigler, Rotor-stator interaction noise studies of a single-stage axial flow research compressor, Journal of the Acoustical Society of America 36 (10) (1964) 20122012, DOI:10.1121/1.1939334.

[7] M. Krack, L. Panning-von Scheidt, J. Wallaschek, C. Siewert, A. Hartung, Reduced order modeling based on complex nonlinear modal analysis and its application to bladed disks with shroud contact, Journal of Engineering for Gas Turbines and Power 135 (2013) 102502-1-8, DOI:10.1115/1.4025002.

[8] A. Millecamps, J. Brunel, P. Dufrénoy, F. Garcin, M. Nucci, Influence of thermal effects during blade- casing contact experiments, in: Proceedings of the ASME IDETC/CIE-DETC2009-86842, San Diego, USA, 2009, DOI:10.1115/DETC2009-86842.

[9] M. Legrand, A. Batailly, B. Magnain, P. Cartraud, C. Pierre, Full three-dimensional investigation of structural contact interactions in turbomachines, Journal of Sound and Vibration 331 (11) (2012) 2578-2601, DOI:10.1016/j.jsv.2012.01.017.

[10] N. Carpenter, R. Taylor, M. Katona, Lagrange constraints for transcient finite element surface contact, International Journal for Numerical Methods in Engineering 32 (1991) 103-128, DOI:10.1002/nme.1620320107.

[11] M. Legrand, A. Batailly, C. Pierre, Numerical investigation of abradable coating removal through plastic constitutive law in aircraft engine, Journal of Computational and Nonlinear Dynamics 7, DOI:10.1115/1.4004951.

[12] A. Sternchüss, E. Balmès, On the reduction of quasi-cyclic disks with variable rotation speeds, Proceedings of the International Conference on Advanced Acoustics and Vibration Engineering (ISMA) (2006) 3925-3939.

[13] R. Craig, C. Bampton, Coupling of substructures for dynamics analyses, AIAA Journal 6 (7) (1968) 1313-1319.

[14] P. Gross, On oscillation types in forced nonlinear oscillators close to harmonic resonance, IMA Journal of Applied Mathematics 53 (1994) 27-43.

[15] N. Jabli, H. Khammari, M. F. Mimouni, Qualitative analysis of periodically forced nonlinear oscillators responses and stability areas in the vicinity of bifurcation cascade, IJCSI Internationl Journal of Computer Science Issues 7 (3) (2010) $17-25$.

[16] J. P. Keener, L. Glass, Global bifurcations of a periodically forced nonlinear oscillator, Journal of Mathematical Biology 21 (1984) 175-190. 